\title{
Experience Report: The Challenges of Teaching beyond the University
}

\author{
José Carlos Souza1, Flávio Renato De Almeida Senefonte1,2, Iane Franceschet De Sousa3, \\ Pâmela Mayara da Silva Cassemiro4, Patrícia Alves De Souza ${ }^{4}$ \\ ${ }^{1}$ Universidade Estadual de Mato Grosso do Sul, Campo Grande, Brazil \\ ${ }^{2}$ Universidade para o Desenvolvimento do Estado e da Região do Pantanal, Campo Grande, Brazil \\ ${ }^{3}$ Universidade Federal de Santa Catarina, Florianópolis, Brazil \\ ${ }^{4}$ Universidade do Planalto Catarinense, Lages, Brazil \\ Email: josecarlossouza@uol.com.br, flaviosenefonte@gmail.com, ianefran@gmail.com,pam.casse@hotmail.com,passpb@gmail.com
}

How to cite this paper: Souza, J. C., De Almeida Senefonte, F. R., De Sousa, I. F., da Silva Cassemiro, P. M., \& De Souza, P. A. (2020). Experience Report: The Challenges of Teaching beyond the University. Creative Education, 11, 1073-1081.

https://doi.org/10.4236/ce.2020.117079

Received: May 25, 2020

Accepted: July 19, 2020

Published: July 22, 2020

Copyright $\odot 2020$ by author(s) and Scientific Research Publishing Inc. This work is licensed under the Creative Commons Attribution International License (CC BY 4.0).

http://creativecommons.org/licenses/by/4.0/

\begin{abstract}
Brazilian medical courses have, since the beginning, been guided by activities in Primary Care of the Unified Health System (SUS), using active learning methodologies. The experience of one of these courses is reported, specifically in the scenario of teaching-service-community integration (TSCI). The overcoming of prejudices with work in SUS, the need for the qualification of preceptors, TSCI planning based on demands and the collective construction of the learning by doing process are discussed as relevant. Many difficulties found in the attempt to articulate education and public service are considered.
\end{abstract}

\section{Keywords}

Medical Education, Health Unified System, Preceptorship, Community, Primary Health Care

\section{Introduction}

In Brazil, the National Curricular Guidelines (NCGs) for medical courses recommend the insertion of students in health service networks, considered as a learning space, since the initial grades; students learn health care, management and education, with an emphasis on primary care (Brazil, 2014). The importance of tertiary care, at the hospital level, in medical training is not overlooked; however, this requires more complex structures for installation and maintenance, as well as more specialized professionals (Souza, Zeferino, \& Ros, 2012).

The Curriculum Change Incentive Project for Medical Courses (PROMED) ensured the resizing of curricula towards the needs of the population, compati- 
bility with SUS proposals and reinforcement of the Family Health Strategy (FHS), flags defended since the reform sanitary. Strategies were devised that can be verified with the new financing programs of the Ministry of Health, such as the National Program for the Reorientation of Professional Training in Health (PROHEALTH) and the Education through Work for Health Program (PET-Health). PROMED was the reference for medical schools in fact implementing the NCGs, which are today the reference for all schools in the country (Souza et al., 2012); this aims to improve the teaching-learning process in the practice scenarios in SUS and the quality of assistance to the population.

This program was agreed with the municipal and state health managers, through the Organizational Public Action Teaching-Health Contracts (COAPES) (Brazil, 2014, 2015), with the principles of clarity of benefits and return for the actors involved, the search for excellence and relevance in health actions, evidence-based practice and cost-effectiveness (Brazil, 2013).

The methodologies that are decided to be used, in the practice scenarios, are crucial for the success in the development of the pedagogical model in primary care (Fertonani et al., 2015). In this regard, the purpose of this report is to present the experience of creating and maintaining the teaching-service-community integration (TSCI) scenario, highlighting the challenges of medical education beyond the university.

\section{Teaching, Service and Community Integration Scenario}

The medical course in question was created in 2014, based on four fundamental pillars: use of active learning methodologies, community-oriented education, diversification of learning scenarios and student-centered education (Brazil, 2013, 2014). This change in the medical education paradigm has become a prerequisite for raising the health level of communities. It is intended a graduate with general, humanistic, critical, reflective and ethical training, developing skills to act at different levels of health care, with actions of promotion, prevention, recovery and rehabilitation of health, in the individual and collective spheres, with responsibility social and commitment to the defense of citizenship, human dignity, the integral health of the human being and having as a transversality in their practice, always, the social determination of the health and disease process (Brazil, 2014).

The course consists of thematic modules with tutorials and theoretical-practical content from its Multidisciplinary Learning Support (MLS); there are annual longitudinal modules such as Medical Skills (MS); Teaching-Service-Community Interaction (TSCI); Communication, Leadership and Management Skills (CLMS) including classes in Brazilian Sign Language (LIBRAS) and experimental English classes; Scientific Initiation and Fundamentals (SIF) and the Elective Modules (UEMS, 2020). The TSCI was planned from the first to the fourth year of the course, inserting the student early in the Primary Care services, under the local supervision of doctors and nurses who act as preceptors, also counting on the academic supervision of teachers of the course. The content of the TSCI must be 
articulated with the content of other theoretical modules, in order to simultaneously promote theoretical-practical integration (UEMS, 2020). This interaction is a constant challenge because, due to certain routines and bureaucratic requirements, the TSCI notebook with its annual program content, is ready even before the planning of some thematic modules, with an asynchrony in the curricular integration.

TSCI's activities are structured through an agreement with the Municipal Health Secretariat, whereby mechanisms are defined so that Health Network professionals, designated preceptors, can receive academics and aggregate them, during a period of four hours a week, to the Family Health Team. For the 1st and 2nd years, the professional who will receive the student will not necessarily have to be a doctor, since the performance of the student will be based on familiarization with the structure and functioning of SUS, and with the organization of primary health care, especially with the Family Health Strategy. In the 3rd and 4 th years, the preceptor must be a doctor, since the activities to be carried out start to be centered on aspects related to medical assistance (UEMS, 2020).

The TSCI coordinator is responsible for organizing the module, summative evaluation, academic record, biweekly meetings with academic supervisors and all preceptors, and articulation with the person in charge at the Municipal Health Department. There is the figure of the academic supervisor, in the total of two for each year of the course; in the same way as preceptors, academic supervision can be exercised by any teacher in the 1st and 2nd years of the course and by a doctor in the 3rd and 4th years (UEMS, 2020). Eight groups of 06 students are constituted, in eight different health units, simultaneously, in the same day and period. It is the responsibility of academic supervision to visit each group, weekly, in order to monitor the performance of preceptors and academics, inform the TSCI coordination about the progress of activities, any difficulties, as well as propose adjustments to the schedule and participate in biweekly meetings. The supervisor's workload is four hours per week with the academic and one hour per week for a meeting with the module coordinator and preceptors (UEMS, 2020).

\section{Pedagogical Aspects of TSCI}

Paulo Freire (2009) affirmed that the practice must be covered with know-how and know-how to be exercised, in which critical reflection on the practice must be a requirement (Freire, 2009). Thus, the methodological choice becomes essential to achieve the professional profile that the new doctor seeks, based on real situations, providing the student with greater appropriation of theory, when associated with practice (Meireles, Fernandes, \& Silva, 2019). The establishment of relations between the university, health services and the community favors the construction of models oriented to the latter (Bandini \& Lucca, 2018). The course in question offers quota of vacancies for indigenous and afro-descendent students, further increasing interest and territory for health care in urban villages and quilombola communities. 
The TSCI method is that of problematization, anchored in the concept of building knowledge from insertion in reality, in an effort to understand, interpret, theorize and intervene in that same reality; motivates the student who, in the face of a real and contextualized problem situation, examines, reflects, relates his story and starts to reframe his discoveries (Maroja, Júnior, \& Noronha, 2020). New learning is a necessary and significant instrument to expand its possibilities and paths (Melo, Boeckmann, Costa, Moura, \& Guilhem, 2016). The Arc of Maguerez, the basis for the application of problematization, is based on the process of action-reflection-action that transforms society; its stages are the observation of reality from a closer look at the problems, which gain repercussion and meaning for the collective; the key points where, in the face of multifactorial and multidimensional problems, there must be criticality in their assessment so that the solution is relevant; the theorization that will support the hypotheses for solving the problem; the hypothesis of solving the problem with the observation of reality, key points and theorizing; and the application to reality, which is where all the problems emerge and where the applications of solutions are directed (Cortes et al., 2018).

\section{Preceptorship in Teaching beyond the University}

The curricular changes were not yet sufficient to affect the understanding of the health-disease process beyond the university. There are some variables such as the lack of motivation, appreciation and perspectives in primary care, by some of the preceptors. This fact does not fail to pass on to academics a negative and ephemeral notion of primary health care; this ends up not arousing their interest in working in primary care in the future. It is constitutional that the SUS is an internship field for the training of health professionals; however, there are difficulties of all kinds for this to happen, among them the harmonious approximation of the service network with the university, the insufficient funding, the emphasis of most teachers in hospital and specialized education, the non-monitoring and the permanent application of a evaluation program on curriculum reform (Souza et al., 2012).

The reciprocal interaction between the managers of the Educational Systems and the SUS will allow the creation of real conditions for the use of both systems, with better technical quality in care and in the teaching-learning process (Souza et al., 2012). In addition, there is an urgent need for greater attention to material and human resources for a more adequate functioning of the Basic Health Units; therefore, the social control of the community is a great ally in this process. The health network and educational institutions must align objectives and goals so that students' early insertion strategies are successful. Thus, it is essential that there is an approximation between teaching and service, with exchanges and advantages for both sectors. In addition to the actors already mentioned, the essential role of community health workers, who live directly in the reality of the population, cannot be ignored here; these testify to various social determinants 
of the health-disease process, such as unemployment, low income, lack of basic sanitation, among other health risks, vulnerabilities and risks.

Most schools have teaching in large areas, with a large part of the workload directed to secondary and tertiary care; however, the NCGs encourage to reorganize and encourage primary care, as a privileged strategy to replace the traditional model of health care organization, removing the focus of the disease and hospital care (Souza, Zeferino, \& Ros, 2011). The beginning of these changes also depends on national social assistance and public health policies; however, it must be taken into account that many public programs and policies do not have continuity due to changes in administrative and electoral direction (Souza et al., 2011).

Ceccim et al. (2016) discuss the difficulties in implementing the TSCI module, with regard to the preparation of the preceptors to the pedagogical aspects used by the course, given that the training of most of them was technicist and focused on traditional teaching. Thus, the insertion of these professionals as preceptors of students who use active teaching-learning methodologies required new investments, such as training on the methodology and the evaluation process of students. The authors emphasize that the coordination of the TSCI module should organize meetings for the training of some preceptors involving the following themes: presentation of the curricular proposal, role of the preceptorship and competence desired to meet the course methodology, student evaluation, collective construction of the evaluation instrument student, group work techniques, how to provide feedback and module evaluation. All meetings can be held through workshops, in order to allow the exchange of experiences between the preceptors, valuing their opinions and, at the same time, pointing out the opportunities for improvement in the preceptor function (Ceccim et al., 2016).

The preceptor is referred to as a health service professional, who accompanies the apprentice, and has an essential role in the insertion of the student or resident in professional practice and in their training process (Oliveira et al., 2017). The role of the preceptor in primary health care is fundamental, being mediated by duties and obligations that work in the FHS routinely proposes. It is up to him to insert academics in this environment, to facilitate the mediation between the health team, municipal secretariat and local management, being assigned goals and objectives of pre-established programs, at the beginning of the module (Rocha et al., 2020). It is also important that, in the role of preceptor, the health worker does not lose sight of his clinical care function already assigned, being necessary to articulate between the population demand and the training demands, in context with the work bureaucracy. One of the ways to facilitate flexibility between preceptors and the entire teaching-management network, in addition to a continuous improvement of work, is the application of the National Policy for Permanent Education in Health (NPPEH) (Oliveira et al., 2017). This corroborates the objectives of Permanent Education in Health $(\mathrm{PEH})$, as both the objectives and the methodology aim to comply with and implement the prin- 
ciples of the constitutional SUS, prioritizing integrality and strengthening social control (Lemos, 2016).

For the process of organizing care in primary care, a coherent bond of PEH must be maintained, valuing the experience and exchanges of knowledge/knowledge of everyday life, building forms of interaction between service/population, or between worker/user (Campos, Marques, Ceccim, \& Silva, 2019). In addition, it must encompass workers, managers, education and assistance, as well as users, through social control (Fertonani et al., 2015; Lemos, 2016). PEH does not aim at centralized knowledge, where there is a knowledge holder, as it believes that this way the real change in practice does not happen (Ceccim, 2005). Some aspects can help in the elaboration of meanings for health practice, such as reestablishing the authentic relationship with oneself and with the work that one does, recognizing himself valiantly as a care worker and producer. This is the space that your doubts, concerns, subjectivations and dissatisfactions can and should be exercised (Brazil, 2005).

\section{Final Considerations}

The co-responsibility of the higher education institution is required, in order to promote reflection on the field of work and to train the student and the service professional in relation to knowledge, skills and attitudes, for a rewarding professional and personal performance. Thus, the means found for ongoing training are the collective spaces of preceptors and teachers, for the discussion of problems in relation to the functions requested and the objectives to be achieved by medical training.

The practice in the primary care setting is considered by many scholars in the field to be a "fertile environment" to develop clinical skills, necessary for health professionals. These activities developed within the PHC are in line with the recommendations of the NCGs of undergraduate medicine. They are focused on an integral approach between health and teaching-service, which should guide the training of medical professionals. It is also worth noting that these new learning methodologies allow the medical student the opportunity to face, from the beginning of the training, the daily life of a community and different health contexts. For this and other reasons, the preceptor must know the problem-based learning (PBL) method, the integrated curriculum of the course and the other scenarios that the student is studying at that moment, in order to better integrate the syllabus.

The use of Primary Care spaces in the training of medical students has become a common goal of the courses, mainly due to the recommendations of the NCGs. However, this scenario is still the source of political and ideological disputes, which sometimes bring a strain on the relationship between the service and the educational institution. In addition, prejudice still prevails in working at SUS, to the detriment of the hegemonic view provided by technological medicine and the specialist job market, which is more financially attractive. Although 
there is a heterogeneity in the training of teachers and preceptors, many of whom have graduated in the traditional curriculum, this reality can be mitigated with a greater appreciation of these actors, better working conditions, adequate continuing education of the PBL method, of the curriculum and Pedagogical Political Project of the course.

Today the primary care scenario is able to occupy a more prominent place, in view of its history of lecture by hospital spaces. Inserting another logic of action such as accountability for care, valuing autonomy and the multiple cultures existing in the territory, exploring subjective aspects and integrating psychosocial knowledge, are part of acting at this level. Such specificities imply a serious work by the academy to sensitize its graduates in this direction.

During the experience of the TSCI module, the lower resistance of the first year was visible, when he was inserted in the health service routine early. The reality disseminated by the media and incorporated in common sense, almost always pejoratively, is impacted when the student hears the following phrases: "I thought it was worse", "wow I was surprised, I didn't think it was so good". However, the work is still arduous in demystifying concepts and prejudices related to Primary Care and SUS.

Other challenges concern the innovative pedagogical aspects, which permeate the choice of methodology, curriculum planning, operational and monitoring aspects, as well as the evaluation of the module and students. The problematization is one of the methodological alternatives that can be applied in this scenario, whose experience in Brazil is still incipient. In this, the opportunity for praxis becomes paramount in the students' learning process, impelling them in understanding, theorizing and solving problems. The scenario of TSCI also requires a thorough curriculum planning, taking into account the lecture of the activities for which the student must be inserted. This should be agreed upon in the pedagogical project of the course, without losing sight of the profile of the graduate's competences.

The evaluation of the implemented program is crucial for its improvement, always taking into account the participation of all the actors involved: students, teachers, preceptors and health managers. The evaluation of students must take into account the training aspects, so that they can have opportunities for growth throughout the process.

The experience demonstrated the difficulty of the preceptors in working in an inclusive sense of the students in the work process, especially due to the difficulties of the health system itself, such as overwork and problems in the infrastructure.

In view of this panorama, it was found that the practice of preceptorship interferes with the quality of the module and the students' learning. Therefore, it is necessary to link health practices with pedagogical practices, in order to transform the organization of services into training practice scenarios. In this way, improvement in the work and health training processes can be achieved, promoting permanent education in public and basic services. 


\section{Conflicts of Interest}

The authors declare no conflicts of interest regarding the publication of this paper.

\section{References}

Bandini, M., \& Lucca, S. R. (2018). From Alma-Ata to Astana: Why Does Primary Health Care Interest Health Professionals at Work? Brazilian Journal of Occupation Medicine, 16, 391-392.

Brazil (2005). Ministry of Health. Training Course for Facilitators of Continuing Education in Health: Learning Unit-Work and Relationships in the Production of Health Care. Rio de Janeiro: Ministry of Health/FIOCRUZ.

Brazil (2013). Presidency of the Republic. Law No. 12,871, of October 22, 2013. Establishes the Mais Médicos Program, Amends Law 8.745, of December 9, 1993, and $n^{\circ} 6.932$, of July 7, 1981, and Other Measures. http://www.planalto.gov.br/ccivil_03/_ato2011-2014/2013/Lei/L12871.htm

Brazil (2014). Ministry of Education. CNE/CES Resolution No. 3, of June 20, 2014. Institutes National Curricular Guidelines for the Undergraduate Course in Medicine. Official Gazette of the Federative Republic of Brazil.

Brazil (2015). Ministry of Health. SUS Managers Support Manual for the Implementation of COAPES. Brasília: Secretary for Labor Management and Health Education, Department of Health Education Management.

https://www.ufjf.br/icvgv/files/2017/06/3.-Manual-de-Apoio-aos-Gestores-do-SUS-par a-implementa\%c3\%a7\%c3\%a3o-do-COAPES.pdf

Campos, K. F. C., Marques, R. C., Ceccim, R. B., \& Silva, K. L. (2019). Permanent Health Education and Assistance Model: Correlations in the Daily Service in Primary Health Care. PHC in Magazine, 1, 132-140. https://apsemrevista.org/aps/article/view/28/26

Ceccim, R. B. (2005). Permanent Health Education: Decentralization and Dissemination of Pedagogical Capacity in Health. Science and Collective Health, 10, 975-986. https://lume.ufrgs.br/handle/10183/20113

Ceccim, R. B. et al. (2016). Expression of the Governmentality Process in Health Care Residencies. Interface-Comunicação, Saúde, Educação, 20, No. 57.

Cortes, L. F., Padoin, S. M. M., \& Berbel, N. A. N. (2018). Problematization Methodology and Convergent Healthcare Research: Praxis Proposal in Research. Brazilian Journal of Nursing, 71, 440-445. https://doi.org/10.1590/0034-7167-2016-0362

Fertonani, H. P., Pires, D. E. P., Biff, D., \& Scherer, M. D. S. (2015). Health Care Model: Concepts and Challenges for Brazilian Primary Care. Science \& Collective Health, 20, 1869-1878. https://doi.org/10.1590/1413-81232015206.13272014

Freire, P. (2009). Pedagogy of Autonomy: Knowledge Necessary for Educational Practice (33rd ed.). São Paulo: Peace and Earth.

Lemos, C. L. P. (2016). Permanent Health Education in Brazil: Education or Permanent Management? Science \& Collective Health, 21, 913-922.

https://doi.org/10.1590/1413-81232015213.08182015

https://www.scielosp.org/pdf/csc/2016.v21n3/913-922/

Maroja, M. C. S., Júnior, J. J. A., \& Noronha, C. A. (2020). The Challenges of Problematizing Training for Health Professionals in a Multiprofessional Residency Program. Interface Communication, Health, Education. https://doi.org/10.1590/interface.180616 https://www.scielo.br/pdf/icse/v24/1807-5762-icse-24-e180616.pdf 
Meireles, M. A. C., Fernandes, C. C. P., \& Silva, L. S. (2019). New National Curriculum Guidelines and Medical Education: Expectations of First Year Students of the Medical Course of a Higher Education Institution. Brazilian Journal of Medical Education, 43, 67-78.

Melo, M. C., Boeckmann, L. M. M., Costa, A. R. C., Moura, A. S. C., \& Guilhem, D. (2016). Problem-Based Learning: Using the Maguerez Arc in Undergraduate Nursing. Electronic Journal of Management \& Health, 7, 247-259.

Oliveira, S. F., Cunha, A. J. L. A., Trajman, A., Teixeira, C., Gomes, M. K., \& Halfoun, V. (2017). Perception of the Medical Internship at the Federal University of Rio de Janeiro by the Preceptors of the Service in Primary Care: A Case Study. Brazilian Journal of Medical Education, 41, 79-85. https://doi.org/10.1590/1981-52712015v41n2rb20160031

Rocha, B. A. S., Lima, I. C. V., Shibuya, B. Y. R., Peixoto, M. G. B., Lima, L. L., \& Magalhães, P. S. F. (2020). Analysis of the Internship in Family and Community Medicine of a Public University of Fortaleza-CE in the Perspective of the Student. Brazilian Journal of Medical Education, 44, e006. https://www.scielo.br/pdf/rbem/v44n1/1981-5271-rbem-44-01-e006.pdf

Souza, P. A., Zeferino, A. M. B., \& Ros, M. A. (2011). Integrated Curriculum: Between Discourse and Practice. Brazilian Journal of Medical Education, 33, 20-25. https://doi.org/10.1590/S0100-55022011000100004

Souza, P. A., Zeferino, A. M. B., \& Ros, M. A. (2012). The Brazilian Public Healthcare System and Its Participation in Medical Training. Health, 4, 500-505. https://doi.org/10.4236/health.2012.48080

UEMS (2020). Pedagogical Project of the Medical Course. Campo Grande: State University of Mato Grosso do Sul.

http://www.uems.br/graduacao/curso/medicina-bacharelado-campo-grande/projeto_p edagogico 